\title{
Commentary: Adjudicating a blood sport?
}

\author{
J. W. Awori Hayanga, MD, MPH, FACS, FRCS, FCCP, ${ }^{a}$ Jeffrey Cannon, MD, ${ }^{b}$ and \\ Heather K. Hayanga, MD, MPH
}

\footnotetext{
From the ${ }^{\mathrm{a}}$ Department of Cardiovascular and Thoracic Surgery, ${ }^{\mathrm{c}}$ Division of Cardiac Anesthesia, WVU Heart and Vascular Institute, West Virginia University, Morgantown, WV; and ${ }^{\mathrm{b}}$ Department of Anesthesia, Case Western Reserve University, Cleveland $\mathrm{OH}$.

Disclosures: Authors have nothing to disclose with regard to commercial support.

Received for publication Aug 27, 2019; revisions received Aug 27, 2019; accepted for publication Aug 27, 2019; available ahead of print Sept 20, 2019.

Address for reprints: J. W. Awori Hayanga, MD, MPH, FACS, FRCS, FCCP, West Virginia University School of Medicine, 1 Medical Center Drive, Morgantown, WV 26505-8059 (E-mail: jeremiah.hayanga@wvumedicine. org).

J Thorac Cardiovasc Surg 2020;160:446

$0022-5223 / \$ 36.00$

Copyright (c) 2019 by The American Association for Thoracic Surgery

https://doi.org/10.1016/j.jtcvs.2019.08.103
}

In this article, Irving and colleagues chronicle the effect of the implementation of blood management guidelines on blood product utilization. ${ }^{1}$ The account adds to a growing body of evidence that suggests that implementation of blood management guidelines might significantly reduce utilization and, as in this account, hospital length of stay. Somewhat remarkably, however, there was no significant improvement in mortality, readmission rate(s), or intensive care unit length of stay. The study is sufficiently powered and draws upon a broad multistate denominator derived from a national data set representative of cardiac surgery patients treated at several hospitals, public and private, each subject to adherence to a single set of national guidelines. The account provides a somewhat stark contrast to reports from health systems such as that in the United States where, with the absence of a national health system, individual hospitals are not beholden to blood product transfusion practices stipulated by the federal government.

The strength of the conclusion is attenuated somewhat, however, by the absence of a suitable control group. This raises the potential for confounding as a direct result of the influence of external factors, independent of the guidelines. It is also worthy of mention that, aside from the guidelines themselves, governmental provisions allowing for monetary incentives to hospitals that show a surplus in annual blood budget(s), are a tacit endorsement of restrictive transfusion policies. Independently this serves undoubtedly, as a potent motivator. Whereas the authors might have addressed the broader support for restrictive blood management, they have also simultaneously, perhaps inadvertently, pointed out the need for an evaluation of perioperative practices that might themselves reduce transfusion needs. These include such methods as hemodilution, retrograde autologous priming, use of short circuit length(s), and intensive care unit anemia protocols among several others. In this vein, a broader multidimensional evaluation of blood usage will remain necessary. As such, as a whole.

\section{References} 160:437-45.e20.

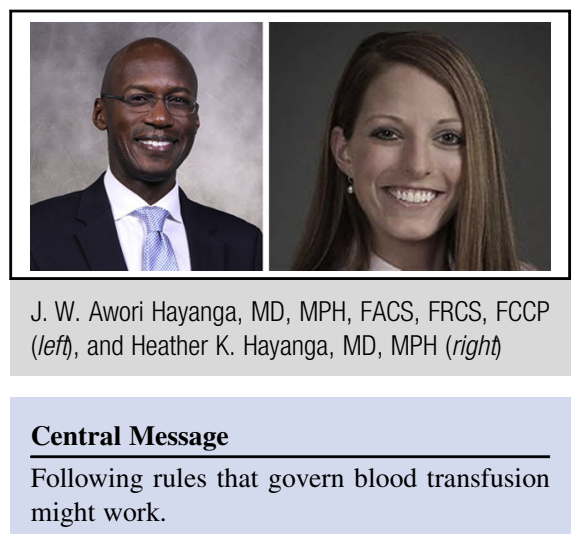

See Article page 437.

blood management guidelines will likely remain a topical issue of vigorous debate.

Admittedly, the growing momentum of support for restrictive policies reads more like a referendum on physician decision-making rather than an unequivocal stance predicated on irrefutable evidence of oxygen deficit as the objective guide to transfusion. Indeed, decisions regarding transfusions as a whole continue to be driven by what might be deemed an emotional response to low hemoglobin level rather than objective metrics of physiological decline. This has been fueled further by the lack of consensus from metaanalyses, thus far. ${ }^{2}$ As such, indication for transfusion solely on the basis of laboratory results will likely remain as much a behavioral as indeed a physiological science. In the interim, however, this report, founded upon a national set of guidelines, provides more evidence that adjudication and policy-making at the national level, replete with monetary incentives, might successfully influence and even reduce the utilization of blood products. On extrapolation, this might serve to reduce health care expenditure because, despite a lack of demonstrable effect on survival, the financial incentives and merits of cost reduction might independently promote the survival of the health system

1. Irving, et al. Impact of patient blood management guidelines on blood transfusions and patient outcomes during cardiac surgery. J Thorac Cardiovasc Surg. 2020;

2. Shehata N, Mistry N, da Costa BR, Pereira TV, Whitlock R, Curley GF, et al. Restrictive compared with liberal red cell transfusion strategies in cardiac surgery: a meta-analysis. Eur Heart J. 2018;40:1081-8. 